\title{
The first case of pancreatoscopy-guided lithotripsy using a novel superpulsed fiberoptic thulium laser
}

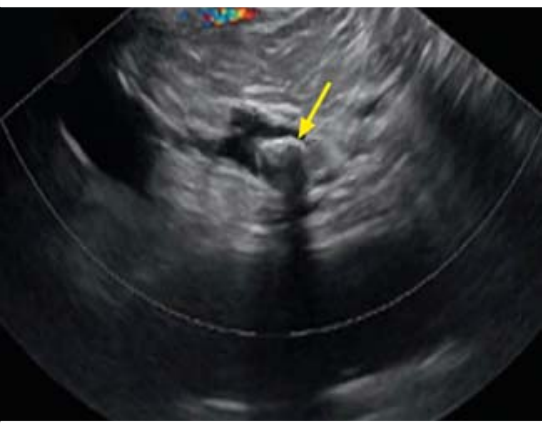

- Fig. 1 Endoscopic ultrasonography image showing main pancreatic duct (MPD) dilatation, with a large MPD stone (arrow) giving an acoustic shadow.

A 50-year-old man with chronic alcoholic pancreatitis was admitted to our hospital with upper abdominal pain and weight loss ( $8 \mathrm{~kg}$ in 5 months). Abdominal ultrasonography and endoscopic ultrasonography (EUS) revealed dilatation of the main pancreatic duct (MPD) up to $13 \mathrm{~mm}$, narrowing of the terminal part of the MPD to $2 \mathrm{~mm}$, and a pancreatic stone $(18 \times 12 \mathrm{~mm}$ in size) located $10 \mathrm{~mm}$ above the orifice ( $\mathbf{F i g . 1}$ ).

We performed endoscopic retrograde cholangiopancreatography (ERCP), endoscopic papillotomy, and pancreatic papillotomy, followed by endoscopic bouginage using Soehendra dilators (Cook Medical) from 4 to $9 \mathrm{Fr}$ and balloon dilation (Boston Scientific; 6-8 mm) of the pancreatic stricture ( $\mathbf{F i g} \mathbf{2}$ ). Peroral pancreatoscopy (Spyglass DS-II; Boston Scientific) was then successfully performed, followed by laser lithotripsy using a novel thulium laser (FiberLase U2; “IRE-Polyus", Russia) (> Fig.3). The laser beam was transmitted via a 400 - $\mu$ m fiber. The surface layer of the pancreatic stone was destroyed in the "dusting" mode (adjusted frequency $60-100 \mathrm{~Hz}$, power $6-10 \mathrm{~W}$, pulse energy $0.1 \mathrm{~J}$ ); then the denser core was fragmented in the "popcorn" mode (frequency $40-60 \mathrm{~Hz}$, power $8-12 \mathrm{~W}$, pulse energy $0.2 \mathrm{~J})$. The stone
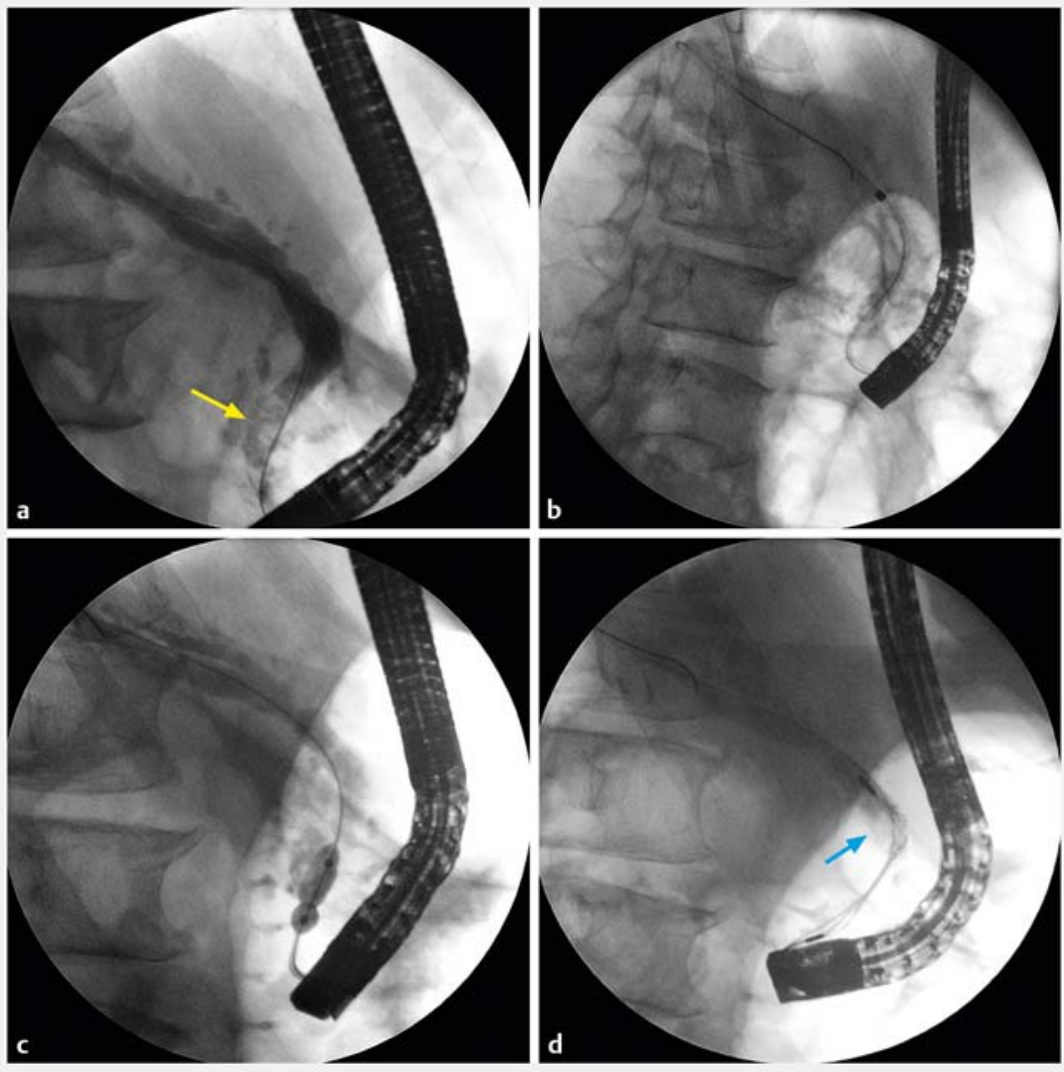

Fig. 2 Endoscopic retrograde cholangiopancreatography images showing: a a large main pancreatic duct (MPD) stone in the head of the pancreas and dilatation of the MPD above the stone; $\mathbf{b}$ endoscopic bouginage being performed; $\mathbf{c}$ balloon dilation of the pancreatic stricture; $\mathbf{d}$ attempted mechanical lithotripsy of the MPD stone (arrow).

was completely destroyed without damaging the soft tissues and was removed from the MPD ( $>$ Video 1 ). The intervention lasted 115 minutes, including 70 minutes of lithotripsy (owing to difficult positioning because of the low stone position). The postoperative period was uneventful, and the patient was discharged on the third day after the intervention.

Currently, there are three main methods of treatment for MPD stones: extracorporeal shock wave lithotripsy, electrohydraulic lithotripsy, and holmium laser lithotripsy [1-3]. A recently released super-pulsed fiberoptic thulium laser has been shown since 2019 to be highly effective in lithotripsy of ureteral stones [4]. Our case, the first of its kind, demonstrates the successful and safe use of this new laser for MPD stone lithotripsy. This promising method could be an alternative to other treatment options for pancreatic stones.

Endoscopy_UCTN_Code_CPL_1AK_2AF 


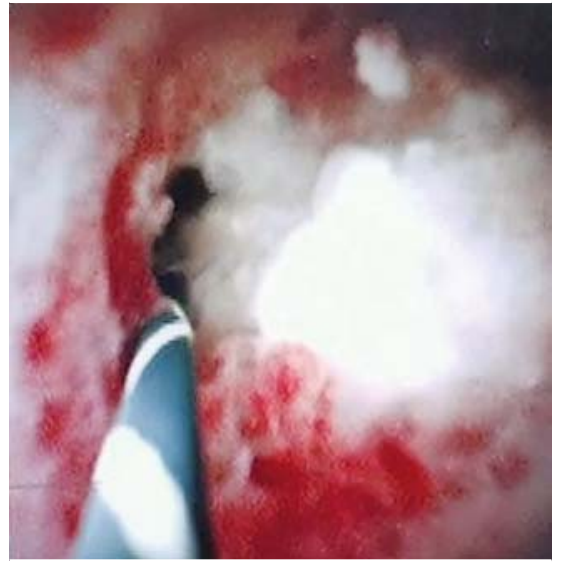

Fig. 3 Pancreatoscopy image showing a large stone obstructing the main pancreatic duct.

\section{Competing interests}

The authors declare that they have no conflict of interest.

The authors

Stanislav A. Budzinskiy ${ }^{1,2}$, Sergey G. Shapovalyants ${ }^{1,2}$, Evgeny Fedorov ${ }^{1,2}$, Elena N. Platonova ${ }^{1}$, Maria A. Anishchenko ${ }^{1,}$ 2 , Elizaveta A. Vorobyeva ${ }^{2}$, Maxim Yu Svirin ${ }^{3}$

1 Moscow University Hospital No. 31 of the Moscow City Health Department, Moscow, Russian Federation

2 Laboratory of Surgical Gastroenterology and Endoscopy, Institute of Clinical Surgery of the Pirogov Russian National Research Medical University, Moscow, Russian Federation

3 UMETEX company, Moscow, Russian Federation

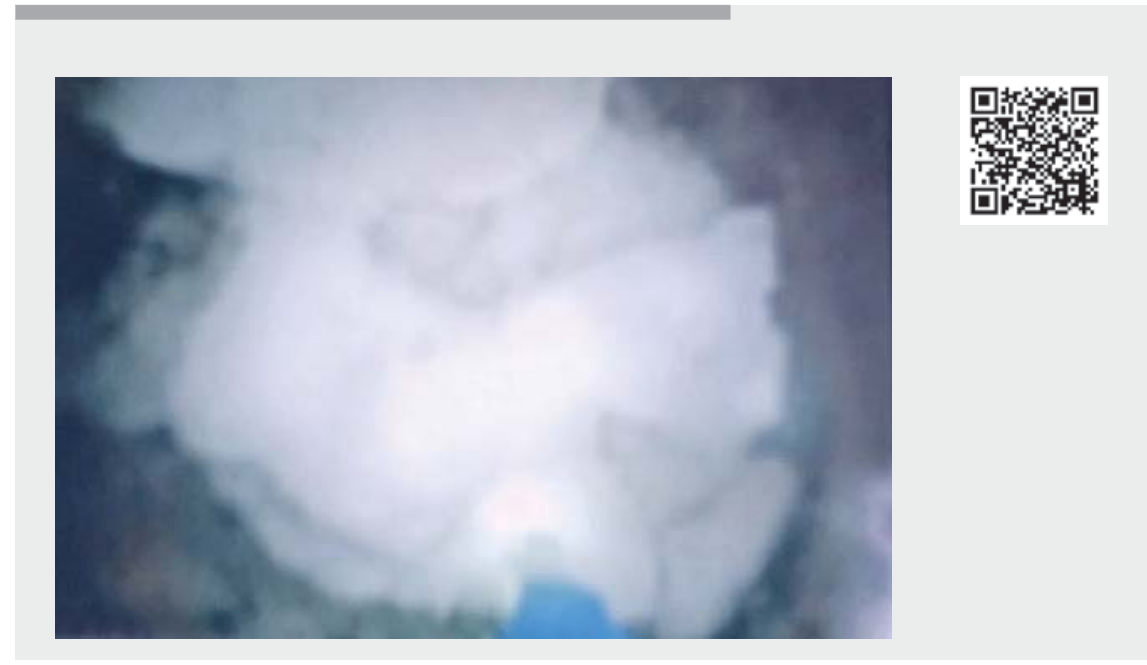

Video 1 Pancreatoscopy-guided lithotripsy using a novel super-pulsed fiberoptic thulium laser.

\section{Corresponding author}

\section{Maria A. Anishchenko, MD}

Laboratory of Surgical Gastroenterology and Endoscopy, Institute of Clinical Surgery of the Pirogov Russian National Research Medical University, 1 Ostrovityanova st., Moscow, 117997, Russian Federation zakharova_mari@mail.ru

\section{References}

[1] Dumonceau JM, Delhaye M, Tringali A et al. Endoscopic treatment of chronic pancreatitis: European Society of Gastrointestinal Endoscopy (ESGE) Guideline - Updated August 2018. Endoscopy 2019; 51: 179-193

[2] Saghir SM, Mashiana HS, Mohan BP et al. Efficacy of pancreatoscopy for pancreatic duct stones: A systematic review and metaanalysis. World J Gastroenterol 2020; 26: 5207-5219

[3] Attwell AR, Patel S, Kahaleh M et al. ERCP with per-oral pancreatoscopy-guided laser lithotripsy for calcific chronic pancreatitis: a multicenter U.S. experience. Gastrointest Endosc 2015; 8: 311-318

[4] Enikeev D, Grigoryan V, Fokin I et al. Endoscopic lithotripsy with a SuperPulsed thulium-fiber laser for ureteral stones: A singlecenter experience. Int J Urol 2021; 28: 261265
Bibliography

Endoscopy 2022; 54: E514-E515

DOI 10.1055/a-1638-8915

ISSN 0013-726X

published online 25.10 .2021

(C) 2021. Thieme. All rights reserved.

Georg Thieme Verlag KG, Rüdigerstraße 14, 70469 Stuttgart, Germany

\section{ENDOSCOPY E-VIDEOS}

https://eref.thieme.de/e-videos

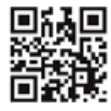

Endoscopy E-Videos is an open access online section, reporting on interesting cases and new techniques in gastroenterological endoscopy. All papers include a high quality video and all contributions are freely accessible online. Processing charges apply (currently EUR 375), discounts and wavers acc. to HINARI are available.

This section has its own submission website at https://mc.manuscriptcentral.com/e-videos 